Article

\title{
Formation and Controlled Drug Release Using a Three-Component Supramolecular Hydrogel for Anti-Schistosoma Japonicum Cercariae
}

\author{
Yibao Li *, Lei Zhu, Yulan Fan, Yayun Li, Linxiu Cheng, Wei Liu, Xun Li and Xiaolin Fan * \\ Key Laboratory of Organo-pharmaceutical Chemistry, Gannan Normal University, Ganzhou 341000, China; \\ zhul@gnnu.cn (L.Z.); fanyl@gnnu.cn (Y.F.); liyy@gnnu.cn (Y.L.); chenglx@gnnu.cn (L.C.); liuw@gnnu.cn (W.L.); \\ wuyq@gnnu.cn (X.L.) \\ * Correspondence: liyb@gnnu.cn (Y.L.); fanx12013@gnnu.cn (X.F.); Tel.: +86-0797-8393536 (Y.L. \& X.F.)
}

Academic Editors: Jonathan Judy and Yoshihiro Ito

Received: 29 December 2015; Accepted: 1 March 2016; Published: 9 March 2016

\begin{abstract}
A novel three-component supramolecular hydrogel based on riboflavin, melamine and amino acid derivatives were constructed for controlled release of pesticides, Niclosamide derivatives. The formation of hydrogel may be attributed to self-assemble via hydrogen bonding and $\pi-\pi$ interaction, which have been researched via scanning electron microscopy (SEM) and Fourier transform infrared (FT-IR) spectra. The rheological experiments showed that the hydrogel materials and drug-loaded hydrogel all demonstrated good mechanical strength and high stability. Further experimental results indicated that the drug-loaded hydrogels show large drug loadings, long-term release time and relatively higher efficiency to anti-cercariae in the water environment.
\end{abstract}

Keywords: hydrogel; drug release; long-term release time; anti-cercariae

\section{Introduction}

Recently, supramolecular hydrogels have attracted intense research interest, particularly due to their possible practical applications in controlled drug delivery [1-3], biomedicine [4], cell culture [5], mechano-responsive sensor materials [6], and pollutant capture and removal [7]. The hydrogelators, amino acids, sugars and steroids can be extracted easily from organisms; therefore, supramolecular hydrogels perform several advantages over the currently polymer gels [8]. In the past ten years, many multicomponent supramolecular hydrogels based on biomolecules have been reported [9-11]. For biological applications, a constant challenge has been finding environmentally friendly molecules to use for controlled drug release [12]. Many small gelator molecules could overcome this problem, since the diversity of functionality is derived from biocompatible components and held together by noncovalent forces [13].

Supramolecular hydrogels are formed through spontaneous aggregation of gelator molecules to structure three-dimensional self-assembled fibrillar networks (SAFINs) [14]. The driving force is mainly derived from intermolecular non-covalent interactions such as hydrogen bonding, $\pi-\pi$ stacking, donor-acceptor interactions, metal coordination, solvophobic forces and van der Waals interactions $[15,16]$. During the multicomponent hydrogel self-sorting process, hydrogen bonding was able to contribute a great amount of driving forces [17]. Recently, two-component hydrogels of riboflavin and melamine, which are suitable for biomedicine and drug delivery systems, have been reported. The formation of the hydrogels could be attributed to the hydrogen bonding interaction between the carbonyl oxygen of riboflavin and the hydrogen atoms of melamine to produce the complexes [18-22].

In addition, $\pi-\pi$ stacking has been generally known to be the intermolecular interaction of the molecules containing an aromatic ring. As an excellent provider of the strong $\pi-\pi$ stacking, perylene 
diimides (PDIs) as versatile ingredients have an enormous application range, such as molecular switches [23], organic lightemitting diodes [24], photoreactive thin films [25], light-harvesting arrays [26], dye lasers, and solar cells [27]. Furthermore, amino acid and its derivatives were, due to their good biocompatibility and environmental friendliness, have been used to build biological materials [28,29], as the favorable gelling agent molecules, amino acid and its derivatives have been used to generate hydrogels with the applications of biological and sensor [30,31].

Schistosomiasis remains a primary, hazardous, rambunctious chronic infections disease in many tropical areas [32]. Shockingly, there are 280,000 deaths annually, 200 million people have been infected, 779 million are at risk of infection, and more than 20 million individuals have experienced high morbidity, all due to schistosomiasis, [33-35]. The cercarial stage has been the only cause of infection, and the most fragile phase in the life cycle of schistosome [36]. Because more than $98 \%$ of cercariae float on water, a thin cercaricide film that can float on the water surface has been able to kill cercariae [37]. There are some drugs that have been able to effectively prevent Schistosoma japonicum cercariae, such as Niclosamide, praziquantel, plants destroyed cercaria drugs, and so on. Unfortunately, these drugs have shortcomings: They have low solubility in water, they are difficult to extract, and the cost is high [38]. To improve the floatation performance of pesticides, the new-type Niclosamide derivatives have been developed by Fan and colleagues [39]. However, in a natural environment, the anti-cercarial results of the Niclosamide derivatives have not been ideal because the pesticides quickly lose their effectiveness in the water soon after they are applied, [40]. Therefore, there is great significance in improving the action time for cercaricide.

Herein, the supramolecular three-component hydrogel based on melamine, riboflavin and amino acid derivatives was constructed via self-assembled behavior. To further study the material, mechanical properties, drug release systems and anti-cercarial ability were investigated.

\section{Results and Discussion}

The chemical structures of $N, N^{\prime}$-dialanine-3,4,9,10-tetracarboxylic diimide (NAPD), riboflavin (RF), melamine (MM) and Niclosamide derivatives (NMD) are shown in Scheme 1. The structure of NAPD demonstrates that it is composed of two parts: the perylene with pronounced capabilities of $\pi-\pi$ stacking and terminal carboxy as remarkable donors and receptors of hydrogen bonds in the gelation process. The structure of RF and MM both contain planar benzene ring structures, which are beneficial for the $\pi$-stacking process. The amidogens of MM and hydroxyls of RF participate in the self-assembly process through the H-bonds. We tested the gelation ability of compounds NAPD with $\mathrm{RF}$ and $\mathrm{MM}$ in a complex solution $\left(\mathrm{THF} / \mathrm{H}_{2} \mathrm{O}=1: 1\right)$ in a typical test-tube experiment. It was found that the NAPD/MM/RF $(1 / 2 / 2)$ system $(0.77 \% w / v)$ was able to generate a rufous and steady gel under ultrasound at $25^{\circ} \mathrm{C}$. In particular, ultrasound was necessary for the gel formation under the same conditions. It was possible for the intermolecular forces, such as hydrogen bonding and $\pi-\pi$ stacking, to obtain enough energy from ultrasound to form network structures.
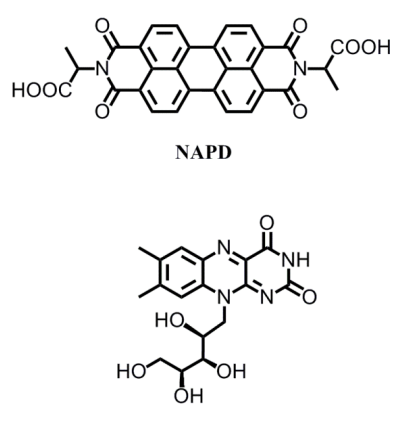

RF

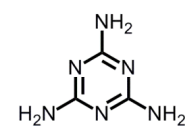

MM

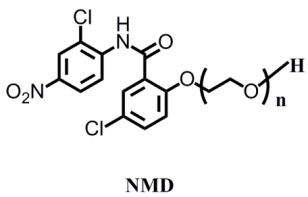

Scheme 1. Chemical structures of $N, N^{\prime}$-dialanine-3,4,9,10-tetracarboxylic diimide (NAPD); melamine (MM); riboflavin (RF) and Niclosamide derivatives (NMD). 
Xerogel samples were observed with scanning electron microscopy (SEM) to investigate the self-assembly structure of gels. The samples were prepared via freeze-drying in a vacuum to protect the microstructures. As shown in Figure 1, fibrous structures were the major constituents in the xerogels of the NAPD/MM/RF (1/2/2) system. Further, the inter-twisted and inter-locked fibers based on the wispy fibrous structure formed the three-dimensional porous network structure, (Figure 1b,c). It was clearly observed that there were many gaps in the network structure, which were a great help in locking the solvent and pharmaceutical molecules.
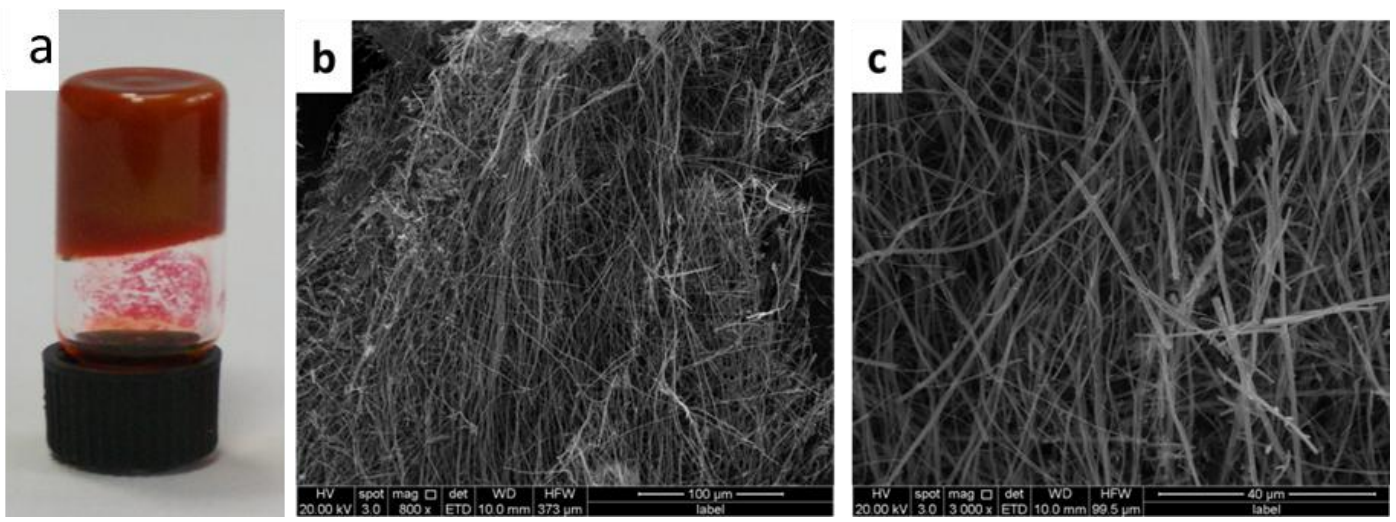

Figure 1. (a) Photo of the gel; scanning electron microscope (SEM) images of the samples (b) for $\mathrm{NAPD} / \mathrm{MM} / \mathrm{RF}([\mathrm{NAPD}]=5 \mathrm{~g} / \mathrm{L}$ ) in larger scale; (c) for NAPD/MM/RF in small scale.

As we know, Fourier transform infrared (FT-IR) spectroscopy is an effective method of investigating intermolecular interactions in the gelation. It could provide some important evidence for understanding the hydrogen bonding interactions in the gel formation. In Figure 2a, the bands of pure NAPD at $1742 \mathrm{~cm}^{-1}$ and $1696 \mathrm{~cm}^{-1}$ correspond to the free carboxyl groups of NAPD, and peaks were shifted to $1700 \mathrm{~cm}^{-1}$, which is indicative of hydrogen bonding $\mathrm{C}=\mathrm{O}$ stretching frequency. The results revealed the formation of the hydrogen bonding in the course of gelation [41,42]. It indicated that the hydrogen bonding between MM, RF and NAPD make great contributions to the formation of the gel.

As an important property, the mechanical performance of a gel material has a great influence on its practical application [35]. To explore the dynamic mechanical properties of the gel, the rheology was characterized by a rheometer. According to Figure $2 b$, in the linear viscoelastic region (LVR), the dynamic storage modulus $\mathrm{G}^{\prime}$ reached $10,000 \mathrm{~Pa}$, and it was larger than the corresponding dynamic loss modulus $G^{\prime \prime}$. As shown in Figure 2c, the results of the frequency sweep for hydrogels revealed that the storage modulus $G^{\prime}$ was larger than the loss modulus $G^{\prime \prime}$ over the investigated oscillating frequency range, and the difference between $G^{\prime}$ and $G^{\prime \prime}$ was nearly unchanged. Figure $2 d$ showed a time sweep at a strain of 30\%, indicating that the viscoelasticity maintained invariability over $6000 \mathrm{~s}$. The above results suggest that this extremely stable hydrogel has excellent mechanical properties.

Drug content is an important parameter for evaluating the properties of the drug-loaded materials. As shown in Figure 3a, it was able to reach the maximum value of the drug content of NMD $(200 \mathrm{mg})$ by $1 \mathrm{~mL}$ NAPD/RF/MM gel $(1.5 \% w / v)$ at the molar ratio of $1 / 2 / 2$ without destroying gel formation. The SEM images show that the drugs were loaded into the intrinsic three-dimensional porous network structure, and that fibrous structures could still be found in the network structure. It has been suggested that the NMD molecule was loaded into the hydrogel materials and formed a stable structure. Next, we further performed the rheology experiments to explore its stability. As plotted in Figure 3b, the value of storage modulus $\mathrm{G}^{\prime}$ was over $10^{4} \mathrm{~Pa}$ and was larger than the corresponding dynamic loss modulus $G^{\prime \prime}$ in the strain sweep, which suggests that the hydrogel was a viscoelastic material. According to Figure $3 c$, the $G^{\prime}$ is always larger than $G^{\prime \prime}$ from $0.01 \mathrm{~Hz}$ to $10 \mathrm{~Hz}$ and their difference basically remains unchanged, which means that the gels were not sensitive to the exoteric force. The time sweep showed that the viscoelasticity of hydrogels did not change in $6000 \mathrm{~s}$ in Figure 3d. 
This suggests that drug molecules were completely wrapped in the hydrogel, and that the stable hydrogel system has good mechanical properties.
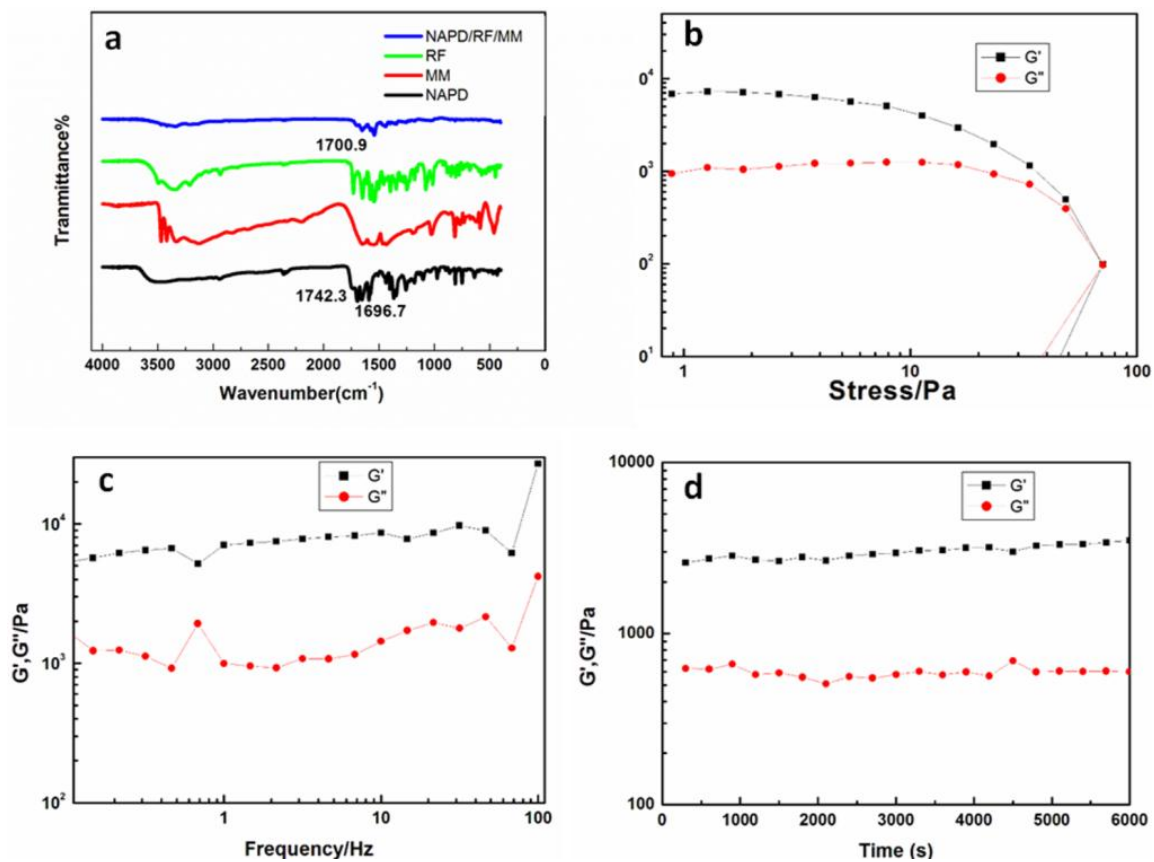

Figure 2. (a) Fourier transform infrared spectroscopy (FT-IR) spectra diluted with $\mathrm{KBr}$ for a $\mathrm{NAPD} / \mathrm{RF} / \mathrm{MM}=1 / 2 / 2$ xerogel (blue), NAPD (black), RF (green), MM (red); (b) strain sweep for NAPD/RF/MM gel at 1.5\% $w / v$ concentration; (c) frequency sweep of the NAPD/MM/RF system at the strain of $0.1 \%$; (d) time sweep of the NAPD/MM/RF gel at the strain of $30 \%$.
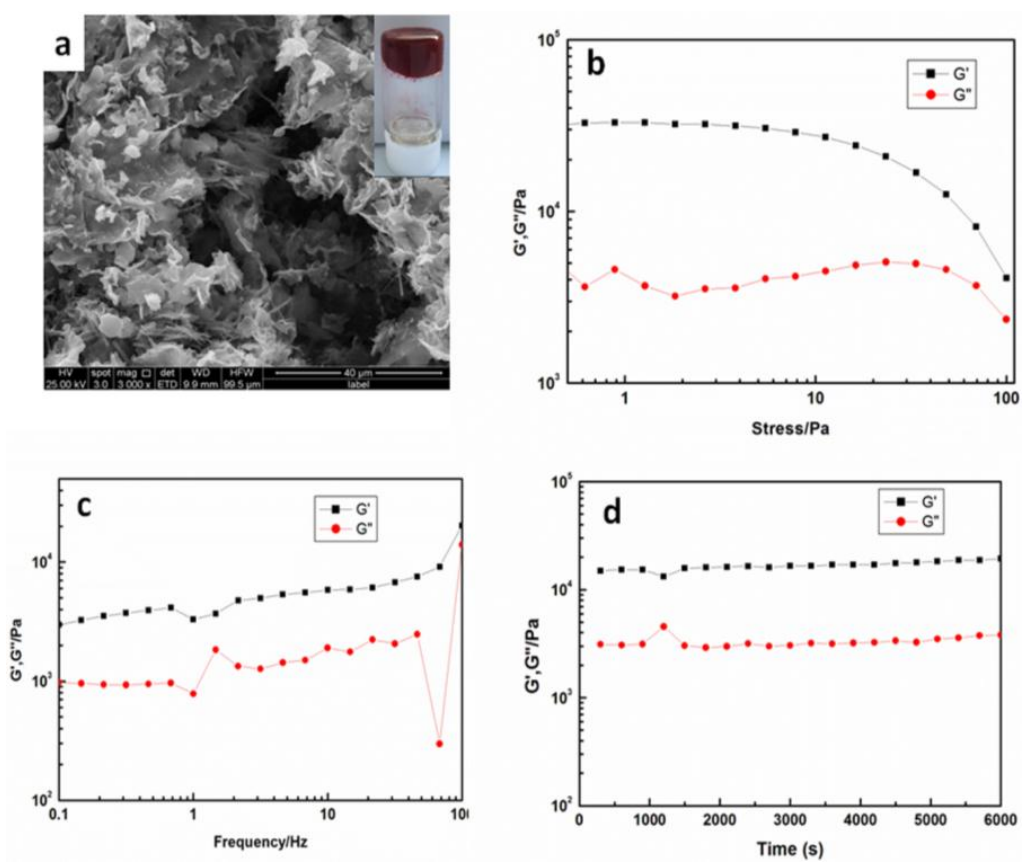

Figure 3. (a) SEM images of the xerogels for NAPD/MM/RF/NMD hydrogel ([NAPD] $=5 \mathrm{~g} / \mathrm{L}$, $[\mathrm{NMD}]=10 \mathrm{~g} / \mathrm{L}$ ) (Insert: Photo of the gel); (b) Strain sweep for NAPD/RF/MM/NMD gel at above concentration; (c) Frequency sweep of the NAPD/RF/MM/Drugs gel at the strain of $0.1 \%$; (d) Time sweep of the NAPD/RF/MM/NMD gel at the strain of $30 \%$. 
Figure 4 showed the release profiles of Niclosamide derivatives from the GP/MM/RF system in water. Figure 4a shows the ultraviolet (UV) absorption standard curves of Niclosamide derivatives at $326.5 \mathrm{~nm}$. The unknown experimental concentration of NMD can be calculated based on the formula $(Y=0.00411+0.0137 X)$ based on the standard curves. Figure $4 b$ shows the release profiles of NMD from the NAPD/MM/RF = 1/2/2 system. It can be observed that about $95 \%$ of NMD was released from the hydrogel over $200 \mathrm{~h}$. Additionally, there was a burst release during the first $50 \mathrm{~h}$, after which the release rate reduced significantly. The results indicate that Niclosamide derivatives can smoothly release into water from the NAPD/MM/RF $=1 / 2 / 2$ system. This drug release system can satisfy the objective of an efficient and long-term cercaricide in a water environment.
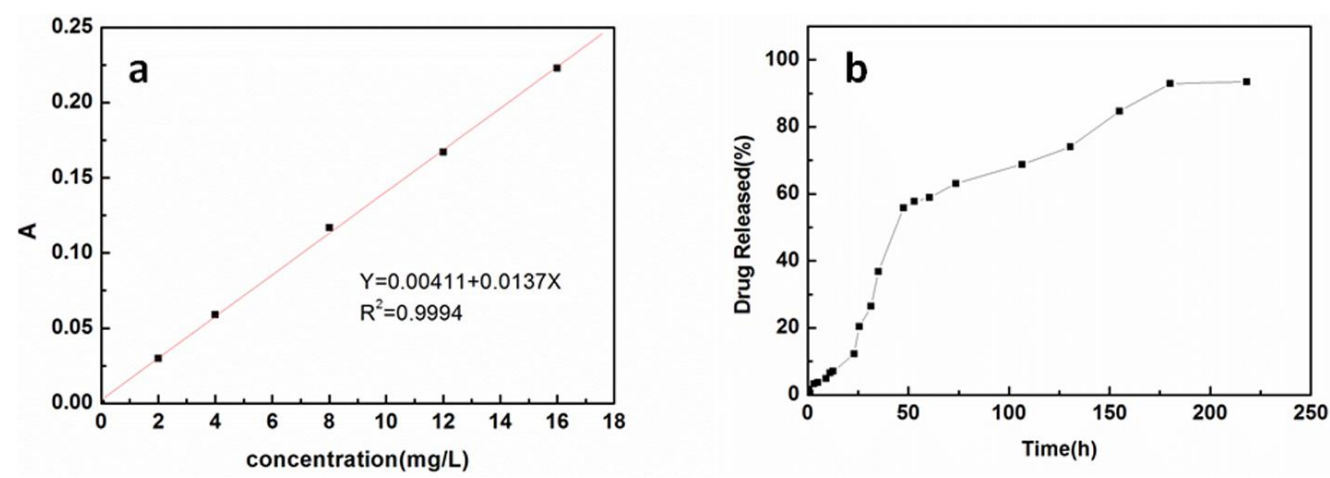

Figure 4. (a) Standard curves of ultraviolet (UV) absorption: Niclosamide derivatives at $326.5 \mathrm{~nm}$; (b) Drug release behavior of NMD from the NAPD/MM/RF $=1 / 2 / 2$ hydrogel at $25^{\circ} \mathrm{C}$ in water.

Further, the anti-cercarial ability of the release system was investigated. The anti-cercarial activity experiment was conducted in a released solution at different release times. As shown in Table 1, the effect of anti-cercarial activity was prominent. Firstly, cercariae was incubated in the solution for $1 \mathrm{~h}$, and the mortality rate of cercariae was nearly 0 . However, after $60 \mathrm{~min}$, the cercariae began to die; the mortality rate reached more than $80 \%$ over $120 \mathrm{~min}$. Further, with added release time, the mortality rate of cercariae can almost reach $100 \%$ in $60 \mathrm{~min}$. Therefore, the hydrogel release system NAPD/MM/RF/NMD maintained commendable bioactivity against cercariae in the water environment.

Table 1. The mortality rate of Schistosoma japonicum cercariae for the hydrogel release system $\mathrm{NAPD} / \mathrm{RF} / \mathrm{MM} /$ Drug $([\mathrm{NAPD}]=5 \mathrm{~g} / \mathrm{L},[$ Drug $]=10 \mathrm{~g} / \mathrm{L})\left(25^{\circ} \mathrm{C}\right)$.

\begin{tabular}{ccccc}
\hline \multirow{2}{*}{ Release Time (h) } & \multicolumn{4}{c}{ Mortality (\%) } \\
\cline { 2 - 5 } & $\mathbf{3 0} \mathbf{~} \mathbf{~ i n}$ & $\mathbf{6 0} \mathbf{~} \mathbf{m i n}$ & $\mathbf{9 0} \mathbf{~ m i n}$ & $\mathbf{1 2 0} \mathbf{~ m i n}$ \\
\hline 1 & 0 & 23.5 & 41.2 & 82.4 \\
2 & 6.67 & 20 & 80 & 100 \\
5 & 85.7 & 100 & 100 & 100 \\
24 & 100 & 100 & 100 & 100 \\
200 & 100 & 100 & 100 & 100 \\
black & 0 & 0 & 0 & 0 \\
\hline
\end{tabular}

${ }^{1}$ All experiments were performed at least in triplicate.

\section{Materials and Methods}

\subsection{Materials}

$N, N$-dialanine-3,4,9,10-tetracarboxylic diimide (NAPD) and the Niclosamide derivatives (NMD) were synthesized and characterized in a laboratory. Double-distilled water (DDW) was used in all experiments. All chemicals and reagents were commercially available and used without further processing. 


\subsection{Synthesis of NAPD}

Under an atmosphere of nitrogen, perylene-3,4,9,10-tetracarboxylic dianhydride (392 mg, $1.0 \mathrm{mmol})$, L-alanine $(0.178 \mathrm{~g}, 2.0 \mathrm{mmol})$ and $2.0 \mathrm{~g}$ imidazole were mixed in a 50-mL flask. Then, the commixtures were stirred at $120{ }^{\circ} \mathrm{C}$ for $6 \mathrm{~h}$, and the resulting emulsion was cooled at $90{ }^{\circ} \mathrm{C}$. $25 \mathrm{~mL}$ of ethanol were added and stirred for $2 \mathrm{~h}$. Subsequently, the mixture was cooled down at room temperature and filtered. Then, the residue was dissolved in $\mathrm{H}_{2} \mathrm{O}$, and $1.0 \mathrm{moL} / \mathrm{L}$ of $\mathrm{HCl}$ was further added dropwise until the water became acidic. After precipitation, the precipitate was filtered and washed with $\mathrm{H}_{2} \mathrm{O}$. The product was dried at room temperature, and mulberry powder was produced (yield: $0.481 \mathrm{~g}, 90 \%$ ). The structure and purity of the product were confirmed by ${ }^{1} \mathrm{H}$ NMR, FT-IR and MS. IR (KBr): $1255.4,1401.6,1590.2 \mathrm{~cm}^{-1}(\mathrm{C}=\mathrm{C}), 1365.5,1436.5 \mathrm{~cm}^{-1}\left(-\mathrm{CH}_{3}\right), 1655.3$, 1696.7, $1742.3 \mathrm{~cm}^{-1}(\mathrm{C}=\mathrm{O}), 2940.5 \mathrm{~cm}^{-1}(\mathrm{C}-\mathrm{H}), 3443.3 \mathrm{~cm}^{-1}(\mathrm{O}-\mathrm{H}){ }^{1}{ }^{1} \mathrm{H}$ NMR (DMSO, $400 \mathrm{MHz}, \mathrm{ppm}$ ): 8.01-8.03 (d, $8 \mathrm{H}), 5.52-5.56(\mathrm{~m}, 2 \mathrm{H}), 1.66-1.68(\mathrm{~d}, 6 \mathrm{H})$; MALDI-TOF-MS: calcd for $\mathrm{C}_{30} \mathrm{H}_{18} \mathrm{~N}_{2} \mathrm{O}_{8}, 534.0$.

\subsection{Characterization}

Nuclear magnetic resonance (NMR) spectra were recorded on an ULTRASHIELD 400 (Bruker, Zürich, Switzerland) spectrometer at $400 \mathrm{MHz}$ at room temperature. Electrospray ionization mass spectra ((ESI-MS)) were obtained by Micromass LCTTM system (Altringham, UK). The FT-IR spectra were carried out using KBr discs on an AVATAR 360 FT-IR spectrophotometer (Nicolet, Madison, WI, USA) at room temperature. UV absorption spectra were performed using a UV-1800 UV-Vis spectrophotometer (Shimadzu, Tokyo, Japan). The morphology of these samples was observed via scanning electron microscopy (FEI, QUANTA 450, Hillsboro, OR, USA) with an accelerating voltage of $20.0 \mathrm{kV}$. The SEM samples were prepared by placing a drop of gel on a flat surface of a cylindrical copper substrate. Then, the hydrogel was dried via freeze-drying for $3 \mathrm{~h}$. Following that, the samples were coated with gold using a MSP-1S magnetron sputter (Japan) coater (Tokyo, Japan). Rheological properties were measured using a HAAKE RheoStress 6000 rheometer (Offenburg, Germany) with plate geometry (plate diameter, $35 \mathrm{~mm}$ ). Frequency sweep measurements were carried out on freshly formed gels over a range from 0.01 to $10 \mathrm{~Hz}$ at $25^{\circ} \mathrm{C}$. Strain sweep was performed at a strain amplitude of $1 \%$. Time sweep measurements were performed at a frequency of $6.28 \mathrm{rad} \cdot \mathrm{s}^{-1}$ and a strain of $30 \%$.

\subsection{Gelation Test}

The gelation test of $\mathrm{N}, \mathrm{N}$-dialanine-3,4,9,10-tetracarboxylic diimide (NAPD), riboflavin (RF) and melamine $(\mathrm{MM})$ in a complex solution $\left(\mathrm{THF} / \mathrm{H}_{2} \mathrm{O}=1: 1\right)$ were performed. To prepare different hydrogel systems at various NAPD:RF:RF molar ratios, generous amounts of NAPD, RF and MM were weighed in glass tubes, and comparable amount of double distilled water was then added after an addition of $0.5 \mathrm{~mL}$ of tetrahydrofuran (THF). They were endured for $2 \mathrm{~h}$ with ultrasonic vibration at room temperature. The results showed that the NAPD:RF:RF hydrogel system at 1/2/2 molar ratio can form steadily and does not flow when the tube is inverted. It was discovered that the minimum gelation concentration for this system is $0.77 \%(w / v)$.

\subsection{Drug Loading Test}

The Niclosamide derivatives (NMD) were used to test the release property of this controlled release system. To investigate the drug loading, different qualities of the NMD were added to $1 \mathrm{~mL}$ of a complex solution (THF/ $\mathrm{H}_{2} \mathrm{O}=1: 1$ ) with $10 \mathrm{mg}$ gels of NAPD, MM and $\mathrm{RF}$ at the molar ratio of $1 / 2 / 2$. Then, the compounds were sustained with ultrasonic treatment for $2 \mathrm{~h}$ at room temperature. The formation of the gels was observed to investigate the maximum drug loadings of this kind of supramolecular gels material. 


\subsection{In Vitro Release}

The release of Niclosamide derivatives (NMD) was obtained from the measurement of absorbance at $326.5 \mathrm{~nm}$ and a standard curve, and expressed as follows: NMD release $(\%)=$ NMD released/NMD total $\times 100 \%$. The $2-\mathrm{mL}$ hydrogel sample with $10-\mathrm{mg}$ gels of NAPD, MM and RF at the molar ratio of $1 / 2 / 2$, which was loaded with $20 \mathrm{mg}$ of NMD, was dried via freeze-drying in a vacuum for $6 \mathrm{~h}$. The drug release research was performed by immersing the xerogels sample in a 150-mL portion of water at $25^{\circ} \mathrm{C}$ and stirring. $0.5 \mathrm{~mL}$ of the solution was taken out from the glass bottle at the planned time, and the equal fresh water was then added to insure the same total solution volume. The concentrations of the NMD were measured by the quantitative determination method at $326.5 \mathrm{~nm}$.

\subsection{Anti-Cercarial Activity Experiments}

According to the in vitro release test, a $300-\mu \mathrm{L}$ solution was removed from the glass in a 96-hole edition at different release times $(1 \mathrm{~h}, 2 \mathrm{~h}, 5 \mathrm{~h}, 24 \mathrm{~h}, 200 \mathrm{~h}$, in this order). S. japonicum cercariae were acquired from the water surface in a conical flask, and the infected $O$. hupensis was soaked with bright lighting for $2 \mathrm{~h}$. The cercariae were removed from the holes, including the above solution, at different release times. The activity of the cercariae was observed every $30 \mathrm{~min}$ via biological microscopy.

\section{Conclusions}

In this paper, a three-component supramolecular hydrogel was successfully fabricated, which was composed of amino acid derivatives, melamine and riboflavin. The FT-IR experimental results revealed that the driving forces are the hydrogen bonding between carboxyls. The hydrogels exhibited excellent mechanical strength and large drug loadings of Niclosamide derivatives. Significantly, the release time of the Niclosamide derivatives can reach 10 days, and the release rate can nearly reach $100 \%$. Finally, the results of the anti-cercarial ability experiment showed that the release system exhibits good efficiency in killing cercariae in a water environment.

Acknowledgments: This work was supported by National Natural Science Foundation of China (Nos. 21303024, 21365003, 21473041, 21463003, 51478123). The Jiangxi Provincial "Ganpo Talents 555 Projects," the Jiangxi Provincial Education Department Fund (KJLD13080), the Jiangxi Outstanding Youth Fund (20153BCB23001), and the Jiangxi Provincial Project of the Scientific and Technological Innovation Team (20152BCB24008) are also gratefully acknowledged.

Author Contributions: Yibao Li and Xiaolin Fan conceived and designed the experiments; Lei Zhu, Yayun Li and Yulan Fan performed the experiments; Lei Zhu and Wei Liu analyzed the data; Linxiu Cheng and Xun Li contributed reagents/materials/analysis tools; Lei Zhu wrote the paper.

Conflicts of Interest: The authors declare no conflict of interest.

\section{Abbreviations}

NAPD $\quad N, N^{\prime}$-dialanine-3,4,9,10-tetracarboxylic diimide

RF riboflavin

MM melamine

NMD Niclosamide derivatives

\section{References}

1. Xing, B.; Yu, C.W.; Chow, K.H.; Ho, P.L.; Fu, D.; Xu, B. Hydrophobic Interaction and Hydrogen Bonding Cooperatively Confer a Vancomycin Hydrogel: A Potential Candidate for Biomaterials. J. Am. Chem. Soc. 2002, 124, 14846-14847. [CrossRef] [PubMed]

2. Sada, K.; Takeuchi, M.; Fujita, N.; Numata, M.; Shinkai, S. Post-polymerization of preorganized assemblies for creating shape-controlled functional materials. Chem. Soc. Rev. 2007, 36, 415-435. [CrossRef] [PubMed]

3. Bowerman, C.J.; Nilson, B.L. A Reductive Trigger for Peptide Self-Assembly and Hydrogelation. J. Am. Chem. Soc. 2010, 132, 9526-9527. [CrossRef] [PubMed] 
4. Nel, A.E.; Madler, L.; Velegol, D.; Xia, T.; Hoek, E.M.V.; Somasundaran, P.; Klaessig, F.; Castranova, V.; Thompson, M. Understanding biophysicochemical interactions at the nano-bio interface. Nat. Mater. 2009, 8, 543-557. [CrossRef] [PubMed]

5. Lim, H.L.; Chuang, J.C.; Tran, T.; Aung, A.; Arya, G.; Varghese, S. Dynamic Electromechanical Hydrogel Matrices for Stem Cell Culture. Adv. Funct. Mater. 2011, 21, 55-63. [CrossRef] [PubMed]

6. Goto, H.; Zhang, H.Q.; Yashima, E. Chiral Stimuli-Responsive Gels: Helicity Induction in Poly(phenylacetylene) Gels Bearing a Carboxyl Group with Chiral Amines. J. Am. Chem. Soc. 2003, 125, 2516-2523. [CrossRef] [PubMed]

7. Kiyonaka, S.; Sugiyasu, K.; Shinkai, S.; Hamachi, I. First Thermally Responsive Supramolecular Polymer Based on Glycosylated Amino Acid. J. Am. Chem. Soc. 2002, 124, 10954-10955. [CrossRef] [PubMed]

8. Estroff, L.A.; Hamilton, A.D. Water Gelation by Small Organic Molecules. Chem. Rev. 2003, 104, 1201-1218. [CrossRef] [PubMed]

9. Roy, B.; Saha, A.; Esterrani, A.; Nandi, A.K. Time sensitive, temperature and pH responsive photoluminescence behaviour of a melamine containing bicomponent hydrogel. Soft Matter 2010, 6, 3337-3345. [CrossRef]

10. Yang, Z.M.; Xu, B. Supramolecular hydrogels based on biofunctional nanofibers of self-assembled small molecules. J. Mater. Chem. 2007, 17, 2385-2393. [CrossRef]

11. Pal, A.; Basit, H.; Sen, S.; Aswalb, V.K.; Bhattacharya, S. Structure and properties of two component hydrogels comprising lithocholic acid and organic amines. J. Mater. Chem. 2009, 19, 4325-4334. [CrossRef]

12. Uhrich, K.E.; Cannizzaro, S.M.; Langer, R.S.; Shakesheff, K.M. Polymeric Systems for Controlled Drug Release. Chem. Rev. 1999, 99, 3181-3198. [CrossRef] [PubMed]

13. Lee, K.Y.; Mooney, D.J. Hydrogels for Tissue Engineering. Chem. Rev. 2001, 101, 1869-1880. [CrossRef] [PubMed]

14. Keller, A. Introductory lecture. Aspects of polymer gels. Faraday Discuss 1995, 101, 1-49. [CrossRef]

15. Wang, R.; Geiger, C.; Chen, L.; Swanson, B.; Whitten, D.G. Direct Observation of Sol-Gel Conversion: The Role of the Solvent in Organogel Formation. J. Am. Chem. Soc. 2000, 122, 2399-2400. [CrossRef]

16. Sakurai, K.; Jeong, Y.; Koumoto, K.; Friggeri, A.; Gronwald, O.; Sakurai, K.; Okamoto, S.; Inoue, K.; Shinkai, S. Supramolecular Structure of a Sugar-Appended Organogelator Explored with Synchrotron X-ray Small-Angle Scattering. Langmuir 2003, 19, 8211-8217. [CrossRef]

17. Mukhopadhyay, S.; Maitra, U. A notable group of low molecular mass natural products that form gel are some of the bile acids. Curr. Sci. 2004, 87, 1666-1683.

18. Zhang, J.W.; Ou, C.W.; Shi, Y.; Wang, L.; Chen, M.; Yang, Z. Visualized detection of melamine in milk by supramolecular hydrogelations. Chem. Commun. 2014, 50, 12873-12876. [CrossRef] [PubMed]

19. Sherrington, D.C.; Taskinen, K.A. Self-assembly in synthetic macromolecular systems via multiple hydrogen bonding interactions. Chem. Soc. Rev. 2001, 30, 83-93. [CrossRef]

20. Saha, A.; Manna, S.; Nandi, A.K. Hierarchical tuning of 1-D macro morphology by changing the composition of a binary hydrogel and its influence on the photoluminescence property. Chem. Commun. 2008, 32, 3732-3734. [CrossRef] [PubMed]

21. Mathias, J.P.; Seto, C.T.; Simanek, E.E.; Whitesides, G.M. Self-Assembly through Hydrogen Bonding: Preparation and Characterization of Three New Types of Supramolecular Aggregates Based on Parallel Cyclic CA3.cntdot.M3 “Rosettes". J. Am. Chem. Soc. 1994, 116, 1725-1736. [CrossRef]

22. Manna, S.; Saha, A.; Nandi, A.K. A two component thermoreversible hydrogel of riboflavin and melamine: Enhancement of photoluminescence in the gel form. Chem. Commun. 2006, 41, 4285-4287. [CrossRef] [PubMed]

23. Wasielewski, M.R. Energy, Charge, and Spin Transport in Molecules and Self-Assembled Nanostructures Inspired by Photosynthesis. J. Org. Chem. 2006, 71, 5051-5066. [CrossRef] [PubMed]

24. Langhals, H. Control of the Interactions in Multichromophores: Novel Concepts. Perylene Bis-imides as Components for Larger Functional Units. Chim. Acta 2005, 88, 1309-1343. [CrossRef]

25. Li, C.; Wonneberger, H. Perylene Imides for Organic Photovoltaics: Yesterday, Today, and Tomorrow. Adv. Mater. 2012, 24, 613-636. [CrossRef] [PubMed]

26. Zhao, Y.; Fan, L.Z.; Zhong, H.Z.; Li, Y.F.; Yang, S.H. Platinum nanoparticle clusters immobilized on multiwalled carbon nanotubes: Electrodeposition and enhanced electrocatalytic activity for methanol oxidation. Adv. Funct. Mater. 2007, 17, 1537-1541. [CrossRef] 
27. Sato, N.; Yoshikawa, M. Valence electronic structure at the interface of organic thin films. J. Electron Spectrosc. Relat. Phenom. 1996, 78, 387-390. [CrossRef]

28. Cui, H.; Webber, M.J.; Stupp, S.I. Self-Assembly of Peptide Amphiphiles: From Molecules to Nanostructures to Biomaterials. Pept. Sci. 2010, 94, 1-18. [CrossRef] [PubMed]

29. Li, X.M.; Kuang, Y.; Shi, J.F.; Gao, Y.; Lin, H.C.; Xu, B. Multifunctional, biocompatible supramolecular hydrogelators consist only of nucleobase, amino acid, and glycoside. J. Am. Chem. Soc. 2011, 133, 17513-17518. [CrossRef] [PubMed]

30. Salick, D.A.; Kretsinger, J.K.; Pochan, D.J.; Schneider, J.P. Inherent antibacterial activity of a peptide-based beta-hairpin hydrogel. J. Am. Chem. Soc. 2007, 129, 14793-14799. [CrossRef] [PubMed]

31. Ikeda, M.; Tanida, T.; Yoshii, T.; Hamachi, I. Rational Molecular Design of Stimulus-Responsive Supramolecular Hydrogels Based on Dipeptides. Adv. Mater. 2011, 23, 2819-2822. [CrossRef] [PubMed]

32. Hotez, P.J.; Molyneux, D.H.; Fenwick, A.; Kumaresan, J.; Sachs, S.E.; Sachs, J.D.; Savioli, L. Control of neglected tropical diseases. N. Engl. J. Med. 2007, 357, 1018-1027. [CrossRef] [PubMed]

33. van der Werf, M.J.; de Vlas, S.; Brookerc, S.; Loomana, C.W.N.; Nagelkerkea, N.J.D.; Habbemaa, J.D.F.; Engelsd, D. Quantification of clinical morbidity associated with schistosome infection in sub-Saharan Africa. Acta Trop. 2003, 86, 125-139. [CrossRef]

34. King, C.H.; Dickman, K.; Tisch, D.J. Reassessment of the cost of chronic helminthic infection: A meta-analysis of disability-related outcomes in endemic schistosomiasis. Lancet 2005, 365, 1561-1569. [CrossRef]

35. Steinmann, P.; Keiser, J.; Bos, R.; Tanner, M.; Utzinger, J. Schistosomiasis and water resources development: Systematic review, meta-analysis, and estimates of people at risk. Lancet Infect. Dis. 2006, 6, 411-425. [CrossRef]

36. Cherfas, J. New weapon in the war against schistosomiasis. Science 1989, 246, 1242-1243. [CrossRef] [PubMed]

37. Wu, Y.Q.; Yang, T.S.; Li, X.; Wu, J.C.; Yi, T.; Li, F.Y.; Huang, C.H.; Fan, X.L. Novel derivatives of Niclosamide synthesis: Its bioactivity and interaction with Schistosoma japonicum cercariae. Dyes Pigments 2011, 88, 326-332. [CrossRef]

38. Devarakonda, B.; Hill, R.A.; Liebenberg, W.; Brits, M.; Villiers, M.M. Comparison of the aqueous solubilization of practically insoluble Niclosamide by polyamidoamine (PAMAM) dendrimers and cyclodextrins. Int. J. Pharm. 2005, 304, 193-209. [CrossRef] [PubMed]

39. Li, Y.B.; Xie, Y.Z.; Liu, C.H.; Guo, W.; Li, X.K.; Li, X.; Zeng, Q.D.; Fan, X.L. Nano-film pesticide for Schistosoma japonicum cercariae: Synthesis, characterization, toxicity and insecticidal effect. RSC Adv. 2013, 3, 19956-19960. [CrossRef]

40. Lowe, D.; Xi, J.Y.; Meng, X.H.; Wu, Z.S.; Qiu, D.C.; Spear, R. Transport of Schistosoma japonicum cercariae and the feasibility of Niclosamide for cercariae control. Parasitol. Int. 2005, 54, 83-89. [CrossRef] [PubMed]

41. Zhang, M.M.; Meng, L.; Cao, X.; Jiang, M.; Yi, T. Morphological transformation between three-dimensional gel network and spherical vesicles via sonication. Soft Matter 2012, 8, 4494-4498. [CrossRef]

42. Li, Y.; Zhou, F.; Wen, Y.; Liu, K.; Chen, L.; Mao, Y.; Yang, S.; Yi, T. (-)-Menthol based thixotropic hydrogel and its application as a universal antibacterial carrier. Soft Matter 2014, 10, 3077-3085. [CrossRef] [PubMed]

(C) 2016 by the authors; licensee MDPI, Basel, Switzerland. This article is an open access article distributed under the terms and conditions of the Creative Commons by Attribution (CC-BY) license (http://creativecommons.org/licenses/by/4.0/). 